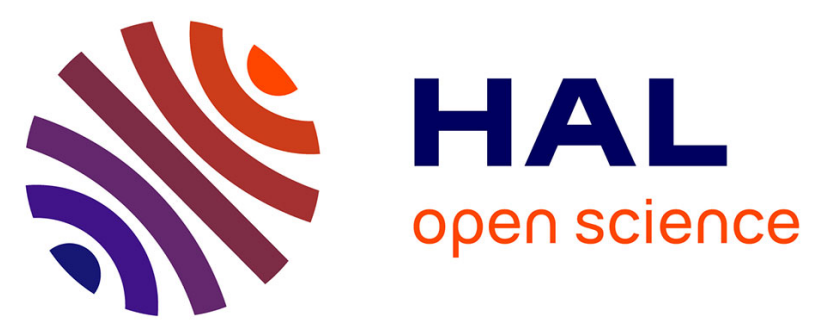

\title{
Supported thin flexible polymethylhydrosiloxane permeable films functionalised with silole groups: new approach for detection of nitroaromatics
}

Kassem Amro, Sébastien Clément, Philippe Dejardin, William Elliott

Douglas, Philippe Gerbier, J.M. Janot, Thierry Thami

\section{To cite this version:}

Kassem Amro, Sébastien Clément, Philippe Dejardin, William Elliott Douglas, Philippe Gerbier, et al.. Supported thin flexible polymethylhydrosiloxane permeable films functionalised with silole groups: new approach for detection of nitroaromatics. Journal of Materials Chemistry, 2010, 20, pp.7100-7103. 10.1039/C0JM01165G . hal-00511098

\author{
HAL Id: hal-00511098 \\ https://hal.science/hal-00511098
}

Submitted on 18 Nov 2020

HAL is a multi-disciplinary open access archive for the deposit and dissemination of scientific research documents, whether they are published or not. The documents may come from teaching and research institutions in France or abroad, or from public or private research centers.
L'archive ouverte pluridisciplinaire HAL, est destinée au dépôt et à la diffusion de documents scientifiques de niveau recherche, publiés ou non, émanant des établissements d'enseignement et de recherche français ou étrangers, des laboratoires publics ou privés. 


\title{
Supported thin flexible polymethylhydrosiloxane permeable films functionalised with silole groups: new approach for detection of nitroaromatics $\dagger$
}

\author{
Kassem Amro, ${ }^{a}$ Sébastien Clément, ${ }^{a}$ Philippe Déjardin, ${ }^{b}$ William E. Douglas, ${ }^{a}$ Philippe Gerbier, ${ }^{* a}$ \\ Jean-Marc Janot ${ }^{b}$ and Thierry Thami ${ }^{* b}$
}

\author{
Received 22nd April 2010, Accepted 4th July 2010 \\ DOI: 10.1039/c0jm01165g
}

\begin{abstract}
Novel re-useable luminescent sensors highly sensitive to quenching by nitroaromatic compounds in both solution and the vapour phase have been developed by covalently bonding a new allyl-substituted silole into substrate-supported crosslinked polymethylhydrosiloxane (PMHS) thin films by Pt-catalyzed hydrosilylation of the $\mathrm{SiH}$ groups.
\end{abstract}

Chemical sensors for detection of traces of explosives, in particular nitroaromatic compounds, are of great current interest for purposes of public security and environmental protection. ${ }^{1-3} \mathrm{~A}$ variety of conjugated polymers have been used as sensors for nitroaromatic explosives detection ${ }^{4}$ including metallole-containing polymers. ${ }^{5,6}$ The first metallole to be used was a polysilole, ${ }^{7}$ polymers ${ }^{8,9}$ and nanoparticles ${ }^{10}$ containing silole groups being of particular interest. Silole molecules and polymers exhibit aggregation-induced emission (AIE) caused by the restricted intramolecular rotations of the peripheral aromatic rings about the axes of the single bonds linked to the central silole cores. ${ }^{11,12}$ The emission is quenched by nitroaromatic compounds, the effect being enhanced by Lewis acid-base interactions between the silacycle and the nitroaromatic compound. ${ }^{13}$

However, polymer-based sensors made from linear uncrosslinked polymers usually suffer from the drawback of polymer leakage into the medium and ensuing shortened lifetime and inefficient analyses. We report here the development of a new family of fluorescent film sensors for which these disadvantages have been overcome, made from thin films of crosslinked resin covalently bonded to the substrate and containing a very low concentration of silole groups. They exhibit the AIE effect owing to restricted intramolecular rotation, ${ }^{12}$ and show enhanced sensitivity to nitroaromatic analytes because of the very low concentration of silole groups. Thus, a new silole bearing an allyl group at silicon has been incorporated into previously reported novel reactive polysiloxane coatings made from polymethylhydrosiloxane (PMHS) polymers crosslinked by the sol-gel process allowing subsequent functionalization by hydrosilylation of the $\mathrm{SiH}$ reactive groups. ${ }^{14-16}$ The films can be used to test for

${ }^{a}$ Labo. CMOS, CNRS UMR 5253, Institut Gerhardt, Université Montpellier II, Place Egène Bataillon, 34095 Montpellier cedex 5, France. E-mail: gerbier@univ-montp2.fr; Fax: +33 467143852; Tel: +33 467143972

${ }^{b}$ Institut Européen des Membranes, ENSCM, Université Montpellier 2, CNRS, Place Eugène Bataillon, 34095 Montpellier cedex 5, France. E-mail: thierry.thami@iemm.univ-montp2.fr; Fax: +33 467149119; Tel: +33467149184

$\uparrow$ Electronic supplementary information (ESI) available: Preparation and characterization of 1 and PMHS films. See DOI: 10.1039/c0jm01165g nitroaromatics present not only in the vapour phase but also in many types of solvent because of the robust nature of the crosslinked network and covalent bonding to the substrate. They can be made in thicknesses ranging from $20 \mathrm{~nm}$ up to $1 \mu \mathrm{m}$. The silole groups are readily accessible, and the sensors can be regenerated by washing with solvents such as chloroform.

The new pale yellow fluorophore 1-allyl-1-methyl-2,3,4,5-tetraphenylsilole (1) was synthesized in 55\% yield by using Curtis's method $^{17}$ in two steps (ESI $\dagger$ ): (a) lithiation of tolane, followed by (b) reaction of the intermediate dilithiotetraphenylbutadiene with allylmethyldichlorosilane (Scheme 1).

Crosslinked polymethylhydrosiloxane (PMHS) thin films of 5\% crosslinking density were prepared by room temperature sol-gel polymerization of methyldiethoxysilane/triethoxysilane $95: 5\left(\mathrm{~mol}^{\mathrm{l}} \%\right)$ sol mixtures deposited by spin-coating on silicon wafer $\mathrm{Si}(100)$ or microscope glass slide substrates freshly activated with "piranha" solution (ESI $\dagger$ ). The substrates bearing PMHS thin films were then cured at $100{ }^{\circ} \mathrm{C}$ in an oven for $10 \mathrm{~min}$. The thickness of the virgin PMHS films was found to be $c a$. $1 \mu \mathrm{m}$ as measured by infrared spectroscopy from the absorbance of the $\mathrm{Si}-\mathrm{H}$ peak at $c a$. $2167 \mathrm{~cm}^{-1}$ and the calibrated absorption coefficient (ESI $\dagger$ ).

The hydrosilylation reaction between the allyl group of $\mathbf{1}$ and the PMHS Si-H function was performed in air by placing the virgin PMHS thin film/substrate samples in a toluene solution of $\mathbf{1}$ in the presence of Karstedt's catalyst for $18 \mathrm{~h}$ at $60{ }^{\circ} \mathrm{C}$ with stirring. The samples were then removed from the reaction mixture, rinsed with toluene and chloroform to remove any physisorbed material, and dried in a stream of dinitrogen (ESI $\dagger$ ). Dioxygen acts as a co-catalyst in hydrosilylation reactions catalyzed by Karstedt's catalyst. ${ }^{18}$ Hydrosilylation of $\mathbf{1}$ with triethoxysilane showed that the reaction is regiospecific at the allyl group.

Previous studies on hydrosilylation by PMHS have shown that the reaction goes essentially to completion. ${ }^{14,15}$ Indeed, in this case too, no IR spectral evidence for any remaining unreacted silole allyl groups

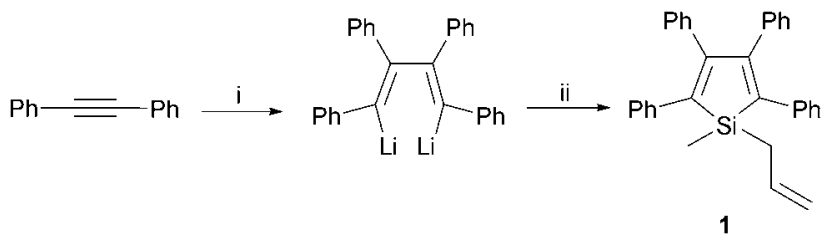

Scheme 1 Synthesis of 1-allyl-1-methyl-2,3,4,5-tetraphenylsilole (1). Reagents and conditions: (i) Li shavings, THF, $12 \mathrm{~h}$ and room temperature; (ii) allylmethyldichlorosilane, THF, $2 \mathrm{~h}$ at room temperature and 5 $\mathrm{h}$ under reflux. 


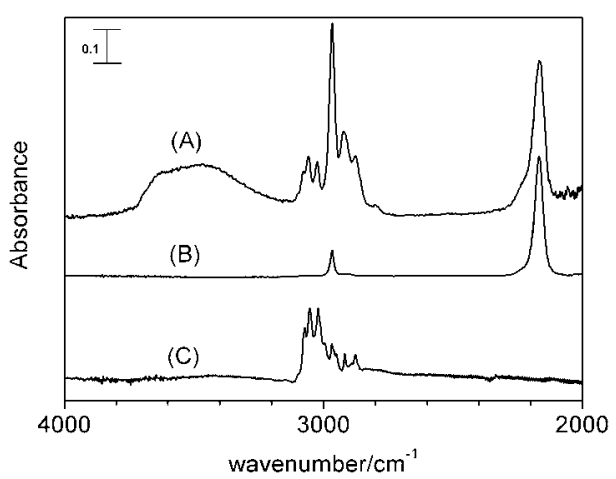

Fig. 1 IR absorption spectra: PMHS film on glass slide (A) after (magnified $\times 10$ ) and $(\mathrm{B})$ before incorporation of $\mathbf{1}$ by hydrosilylation; (C) $\mathbf{1}$ in $\mathrm{KBr}$.

present in the thin films was observed. The degree of silole incorporation into the thin films was found to be $7-8 \%$ from the normalized IR absorbance ratio of the methylene group $\nu_{\text {as }}\left(\mathrm{CH}_{2}\right)$ antisymmetric stretch at $c a .2922 \mathrm{~cm}^{-1}$ (Fig. 1) and the $\nu(\mathrm{SiH})$ band at $c a .2167 \mathrm{~cm}^{-1}$ for the unreacted sample (virgin PMHS), all the methylene groups originating from the silole allyl groups (ESI $\dagger$ ). As expected, the total intensity of the methylene absorbance corresponded to three methylene groups per silole following complete hydrosilylation of $\mathbf{1}$ and covalent bonding into the PMHS network. The residual $\mathrm{SiH}$ function was determined to be $c a$. 15-17\% from the IR spectra by measuring the total integrated absorbances of the $\nu(\mathrm{SiH})$ bands in the 2100-2300 $\mathrm{cm}^{-1}$ region for the reacted and unreacted samples (Fig. 1).

To summarize, $15-17 \%$ of the $\mathrm{SiH}$ groups remained unreacted, 7$8 \%$ underwent hydrosilylation, and the remainder ( $c a .75 \%$ ) underwent reaction with water (present from air moisture) catalyzed by Karstedt's catalyst ${ }^{18}$ (Scheme 2 ) as confirmed by the increase in the IR Si-O-Si stretch band at $c a .1100 \mathrm{~cm}^{-1}$ and the $\mathrm{Si}-\mathrm{OH}$ band at $c a$. $3500 \mathrm{~cm}^{-1}$ observed after hydrosilylation of 1 with the PMHS films. The formation of additional $\mathrm{Si}-\mathrm{O}-\mathrm{Si}$ crosslinks serves to strengthen the film resistance.

The UV/visible absorption and emission spectra of the thin films confirm the presence of silole groups showing a characteristic absorption band at $c a$. $370 \mathrm{~nm}$ assigned to the silole $\pi-\pi^{*}$ transition (Fig. 2(a)) and an intense emission band at $485 \mathrm{~nm}$ (Fig. 2(b)). The spectra remain unchanged after repeated washing of the samples with chloroform, thus confirming the covalent bonding of the silole groups

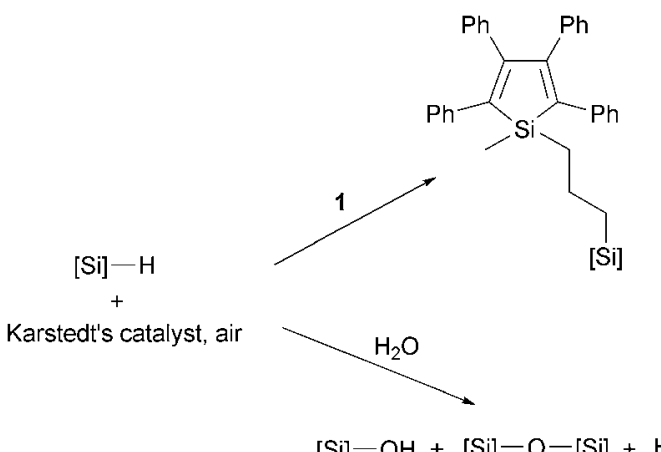

Scheme 2 Reactions of PMHS (represented by [Si]-H) in the presence of Karstedt's catalyst and air: hydrosilylation of $\mathbf{1}$ and reaction with $\mathrm{H}_{2} \mathrm{O}$.
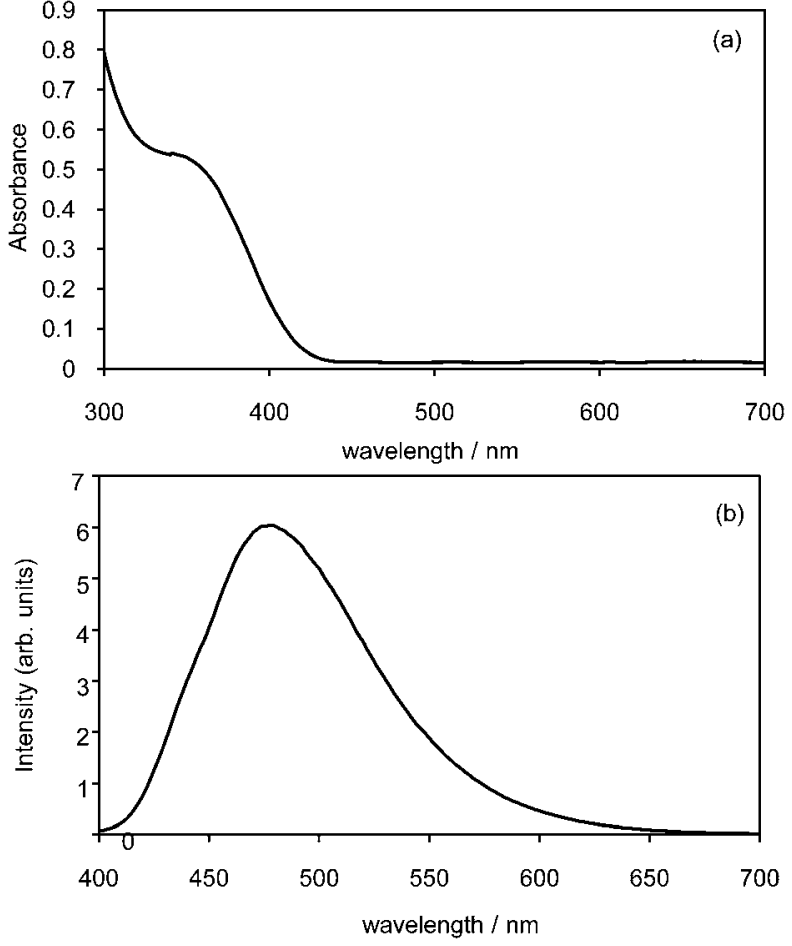

Fig. 2 (a) UV/visible absorption, and (b) emission spectra $\left(\lambda_{\text {excit. }}=375\right.$ $\mathrm{nm})$ of PMHS film containing $\mathbf{1 .}$
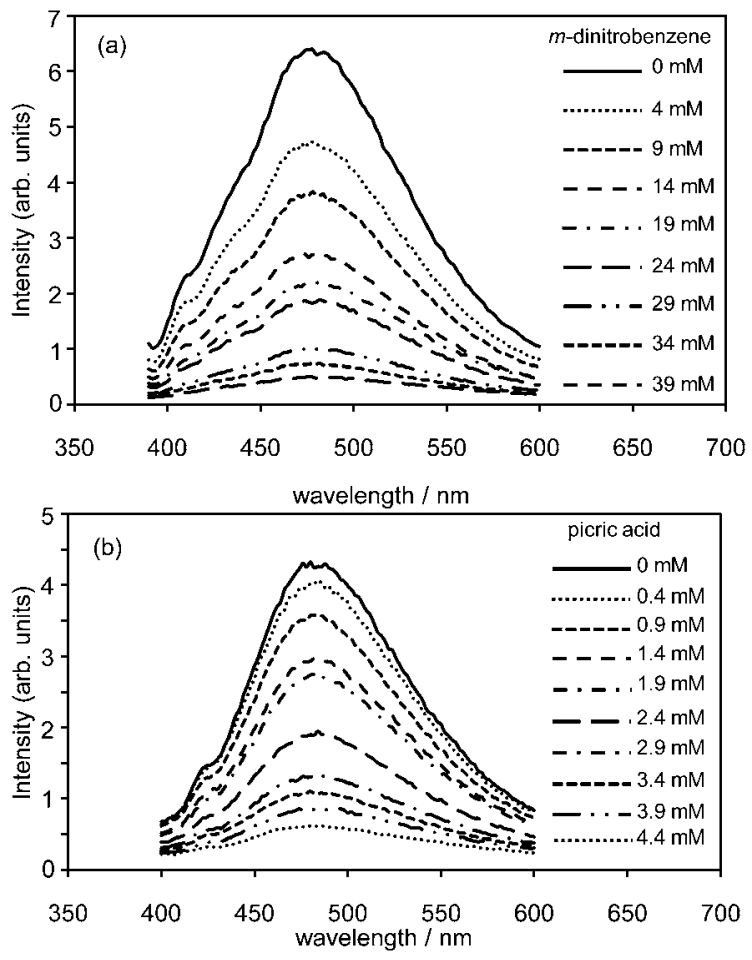

Fig. 3 Decrease in emission intensity $\left(\lambda_{\text {excit. }}=375 \mathrm{~nm}\right)$ of chloroform solution of $1\left(10^{-5} \mathrm{M}\right)$ with increasing concentration of (a) $m$-dinitrobenzene, and (b) picric acid. 

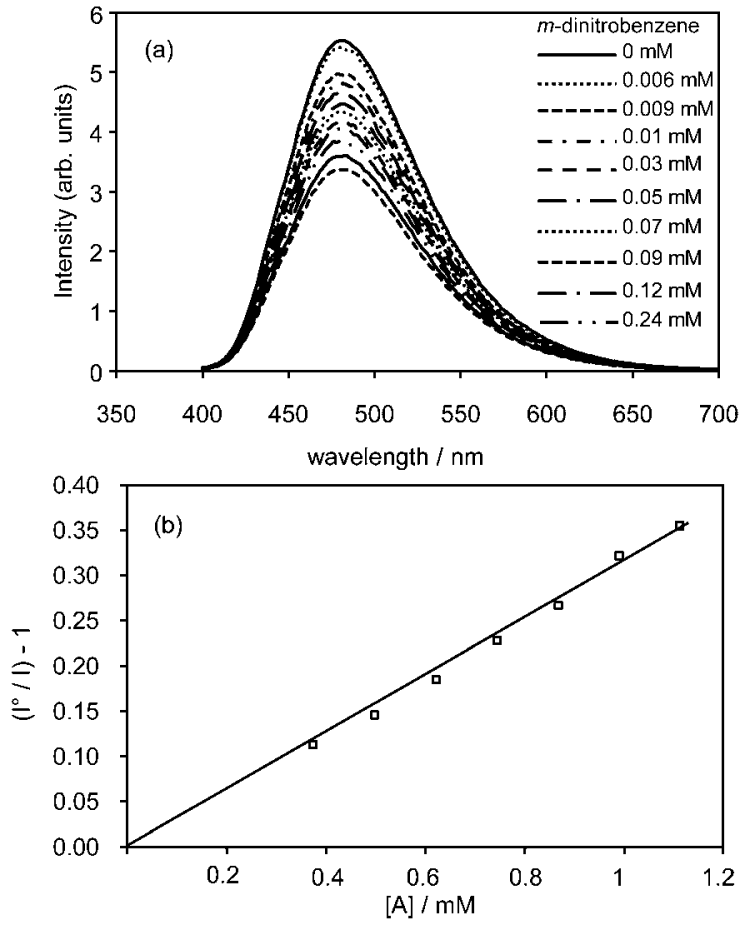

Fig. 4 (a) Emission spectra $\left(\lambda_{\text {excit. }}=375 \mathrm{~nm}\right)$ and (b) Stern-Volmer plot for sample of PMHS containing 1 immersed in chloroform solution with increasing concentration of $m$-dinitrobenzene.

to the PMHS matrix and ruling out physisorption. The silole-containing PMHS films retain their fluorescent properties for at least 3 months in air, and the $\mathrm{Si}-\mathrm{H}$ groups in PMHS gels are stable. ${ }^{16}$

The ability of the new silole to act as a nitroaromatic sensor was first studied in solution. Fluorimetric analysis of a solution of $\mathbf{1}$ in chloroform $\left(10^{-5} \mathrm{M}\right)$ containing increasing amounts of $m$-dinitrobenzene (Fig. 3(a)) and picric acid (Fig. 3(b)) showed the expected fluorescence quenching attributed to Lewis acid-base interactions between the silole silicon centres and the lone pairs of the nitro groups of the nitroaromatic analyte, providing a bridging bond through which electron transfer occurs from the excited state of the silole to the analyte. ${ }^{13}$

Similar results were observed for a thin film of PMHS containing 1. The sample was immersed in a chloroform solution and increasing amounts of $m$-dinitrobenzene (Fig. 4) and picric acid (Fig. 5) were added. The emission spectra show that the quenching effect increases with the concentration of $m$-dinitrobenzene (Fig. 4) or picric acid (Fig. 5).

No corrections for inner filter effects or analyte absorption in the emission spectra were made since, firstly, re-absorption of emitted photons in the ultra-thin PMHS films can be neglected and, secondly, a front-face setup with an optical path of $c a .1 \mathrm{~cm}$ and extremely low analyte concentrations were used.

In the case of the $m$-dinitrobenzene solution, the emission spectra did not change with time of immersion. However, after the sample had been immersed for $1 \mathrm{~h}$ in the picric acid solution, the emission intensity decreased markedly ( $c f$. Fig. 5(a), the two measurements in the presence of $0.025 \mathrm{mM}$ picric acid) consistent with some secondary reaction occurring between the silole groups and picric acid. This is reflected in the hiatus exhibited by the Stern-Volmer plot (Fig. 5(b)).
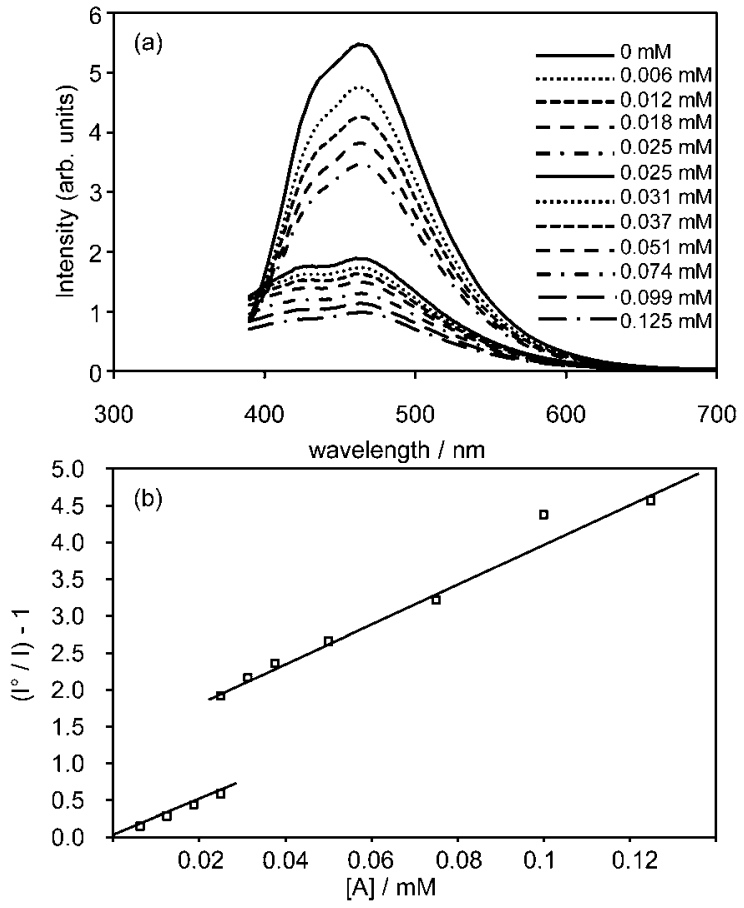

Fig. 5 (a) Emission spectra $\left(\lambda_{\text {excit. }}=375 \mathrm{~nm}\right)$ and (b) Stern-Volmer plot for sample of PMHS containing $\mathbf{1}$ immersed in chloroform solution with increasing concentration of picric acid (a period of $1 \mathrm{~h}$ passed between the two measurements in the presence of $0.025 \mathrm{mM}$ picric acid).

In the case of the $m$-dinitrobenzene analyte the quenching effect is found to be reversible. Simple washing of the detector film with chloroform regenerates the initial fluorescence peak with the same intensity and form (Fig. 6(B)) as for the pristine film (Fig. 6(A)). The same procedure of washing with chloroform the sensor film treated with picric acid gives rise to an emission spectrum of lower intensity and showing two peaks at 408 and $455 \mathrm{~nm}$ (Fig. 6(C)). This behaviour is consistent with the formation of a new fluorescent product by reaction of the silole groups and picric acid. Indeed, with picric acid the quenching effect has been found previously to be partly irreversible in some cases. ${ }^{7,19}$

Studies on the new sensor films are continuing, in particular concerning the effect of nitroaromatic compounds in the vapour phase.

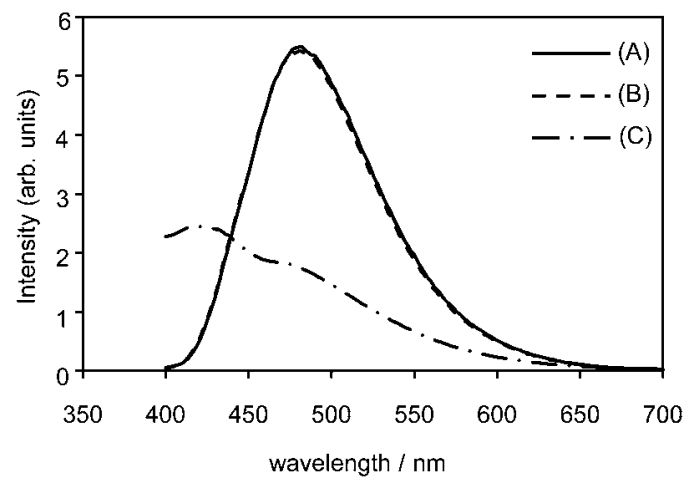

Fig. 6 Emission spectra $\left(\lambda_{\text {excit. }}=375 \mathrm{~nm}\right)$ of sample of PMHS containing 1: (A) pristine film, (B) after immersion in chloroform solution containing $m$-dinitrobenzene followed by rinsing with chloroform, and (C) after immersion in chloroform solution containing picric acid followed by rinsing with chloroform. 
Preliminary results indicate that the films are very sensitive exhibiting almost instantaneous visible quenching, the effect being reversible after $c a$. $1 \mathrm{~h}$ in ambient air.

Financial support was received from the Agence Nationale de la Recherche and the CNRS.

\section{Notes and references}

1 D. T. McQuade, A. E. Pullen and T. M. Swager, Chem. Rev., 2000, 100, 2537-2574.

2 M. Krausa and A. A. Reznev, Vapour and Trace Detection of Explosives for Anti-Terrorism Purposes, Kluwer Academic Publishers, Boston, 2004.

3 S. W. Thomas, G. D. Joly and T. M. Swager, Chem. Rev., 2007, 107, 1339-1386.

4 S. J. Toal and W. C. Trogler, J. Mater. Chem., 2006, 16, 2871-2883.

5 H. Sohn, M. J. Sailor, D. Magde and W. C. Trogler, J. Am. Chem. Soc., 2003, 125, 3821-3830.

6 S. J. Toal, J. C. Sanchez, R. E. Dugan and W. C. Trogler, J. Forensic Sci., 2007, 52, 79-83.

7 H. Sohn, R. M. Calhoun, M. J. Sailor and W. C. Trogler, Angew. Chem., Int. Ed., 2001, 40, 2104-2105.
8 J. C. Sanchez and W. C. Trogler, J. Mater. Chem., 2008, 18, 31433156.

9 J. C. Sanchez, S. A. Urbas, S. J. Toal, A. G. DiPasquale, A. L. Rheingold and W. C. Trogler, Macromolecules, 2008, 41, 1237-1245.

10 S. J. Toal, D. Magde and W. C. Trogler, Chem. Commun., 2005, 54655467.

11 J. Liu, J. W. Y. Lam and B. Z. Tang, J. Inorg. Organomet. Polym. Mater., 2009, 19, 249-285.

12 J. Chen, C. C. W. Law, J. W. Y. Lam, Y. Dong, S. M. F. Lo, I. D. Williams, D. Zhu and B. Z. Tang, Chem. Mater., 2003, 15, $1535-1546$.

13 J. C. Sanchez, A. G. Di Pasquale, A. A. Mrse and W. C. Trogler, Anal. Bioanal. Chem., 2009, 395, 387-392.

14 T. Thami, G. Nasr, H. Bestal, A. V. D. Lee and B. Bresson, J. Polym. Sci., Part A: Polym. Chem., 2008, 46, 3546-3562.

15 G. Nasr, H. Bestal, M. Barboiu, B. Bresson and T. Thami, J. Appl. Polym. Sci., 2009, 111, 2785-2797.

16 T. Thami, B. Bresson and C. Fretigny, J. Appl. Polym. Sci., 2007, 104, 1504-1516.

17 M. D. Curtis, J. Am. Chem. Soc., 1969, 91, 6011-6018.

18 L. N. Lewis, J. Am. Chem. Soc., 1990, 112, 5998-6004.

19 G. He, H. Peng, T. Liu, M. Yang, Y. Zhang and Y. Fang, J. Mater. Chem., 2009, 19, 7347-7353. 